\title{
PAX8 expression in human bladder cancer
}

\author{
LUCIA PELLIZZARI ${ }^{1}$, CINZIA PUPPIN ${ }^{3}$, LAURA MARIUZZI ${ }^{2}$, FRANCESCA SARO $^{2}$, MAURA PANDOLFI $^{2}$, \\ ROBERTO DI LAURO ${ }^{4}$, CARLO ALBERTO BELTRAMI $^{2}$ and GIUSEPPE DAMANTE ${ }^{1,3}$ \\ ${ }^{1}$ Istituto di Genetica; ${ }^{2}$ Istituto di Anatomia Patologica, Policlinico Universitario di Udine; ${ }^{3}$ Dipartimento di Scienze \\ e Tecnologie Biomediche, Università di Udine; ${ }^{4}$ Stazione Zoologica A. Dohrn, Napoli, Italy
}

Received March 31, 2006; Accepted May 30, 2006

\begin{abstract}
PAX8 is a transcription factor with a role in ontogenesis of the urinary tract. The aim of the present investigation was to investigate PAX8 expression in normal bladder and in non-invasive urothelial tumours. Nine cases of normal urothelial mucosa, 2 cases of papillary urothelial neoplasia of low malignant potential, 12 cases of low grade non-invasive papillary urothelial carcinoma and 16 cases of high grade non-invasive papillary urothelial carcinoma were investigated by immunohistochemistry. PAX 8 mRNA expression was evaluated by RT-PCR in a different set of normal bladder mucosas and tumours. In addition, PAX8 expression was evaluated by RT-PCR in bladder from 2 human embryos and in several continuous cell lines derived from bladder tumours (5637, RT-112, TCC-SUP, HT 1376). In immunohistochemical studies, PAX8 was expressed in 28 out of 30 non-invasive urothelial tumours, but not in the normal adult bladders. In RT-PCR studies, PAX8 was expressed in 13 out of 13 bladder tumours but not in the 6 normal bladder mucosa. Contrary to that in adults, PAX8 was expressed in 2 cases of bladder mucosa from 16-week-old embryos. PAX8 was expressed in all the cell lines from bladder tumours. Both in the bladder tumours and cell lines PAX8 expression was highly heterogeneous in terms of the splicing isoforms. Treatment of cell lines with sodium butyrate $(\mathrm{NaB})$ induced several changes of the splicing isoforms. Therefore, only subsets of molecular events that determine the PAX8 mRNA splicing heterogeneity in bladder tumours are sensitive to $\mathrm{NaB}$ treatment.
\end{abstract}

\section{Introduction}

PAX genes encode for a family of transcription factors identified by sequence homology with Drosophila melanogaster paired genes, which is important in the early embryo development (1). PAX proteins play a critical role

Correspondence to: Professor Giuseppe Damante, Dipartimento di Scienze e Tecnologie Biomediche, Piazzale Kolbe 1, 33100 Udine, Italy

E-mail: gdamante@makek.dstb.uniud.it

Key words: bladder cancer, PAX8, differential splicing in cell differentiation and development (2). They are characterized by a 125-amino acid-long DNA-binding motif, named paired domain (2). PAX proteins have been shown to play a crucial role in the early phases of embryogenesis as well as in differentiation and in the maintenance of a differentiated phenotype (3). Moreover, they have been shown to be involved in tumorigenesis, acting as oncogenes in transforming cultured fibroblasts when overexpressed (4). In the mammalian genome, the PAX gene family is composed of 9 members, grouped in four different classes (5). Inactivating mutations of PAX genes induce several developmental abnormalities both in the mouse and humans (6).

During development, the human PAX8 gene is expressed in the thyroid, kidneys, several areas of the central nervous system and the placenta. In the adult, PAX8 is expressed only in thyroid follicular cells, where it contributes to the maintenance of the differentiated state (7).

In kidney development, PAX8 is expressed in pro-, meso-, and metanephros, in particular during the mesenchyma-toepithelium transition (8) and its expression pattern partially overlaps with that of PAX2 (9). Knock-out mouse analysis revealed that kidney organogenesis is normal in PAX8 mutant mice that die postnatally of thyroid defects (10); nevertheless, analysis of PAX2-PAX8 double mutants show that these transcription factors share redundant functions in kidney development supporting the hypothesis of their alternative role in nephric lineage specification (11).

PAX8 and PAX2 are expressed in a high percentage of Wilms' tumours $(9,12,13)$ and both factors are able to activate the WT1 gene promoter $(14,15)$. PAX5, PAX2 and PAX8 proteins are involved in the transcriptional repression of the p53 gene, suggesting a role in tumour initiation and progression (16).

Inactivating mutations of the PAX8 gene in humans cause thyroid dysgenesia and, consequently, congenital hypothyroidism (17). PAX8 expression is reduced in thyroid tumours, with an inverse relationship with the differentiation state of the neoplasm (18).

Bladder cancer is the fourth most commonly diagnosed malignancy in males and the twelfth in females in the United States (19). Urothelial carcinomas (UCs) comprise about $90 \%$ of all bladder primary tumours and, according to the WHO classification, they are classified in non-invasive and infiltrating UCs (20). UC has been investigated by molecular analysis (21-23). In this study, the expression of PAX8 was 

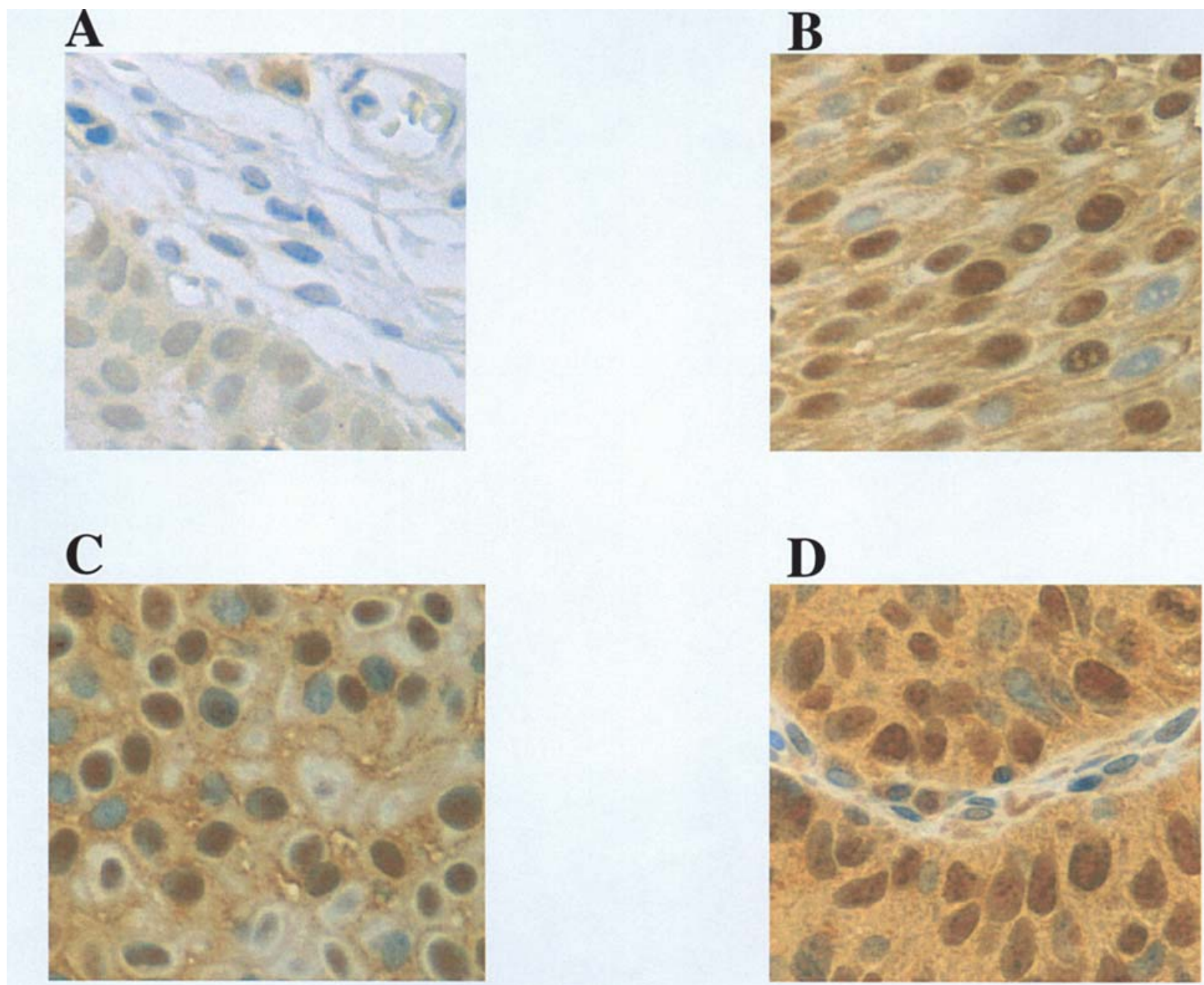

Figure 1. Immunohistochemical staining of the PAX8 protein in normal bladder and UCs. Immunohistochemical detection of PAX8 in normal bladder mucosa and non-invasive urothelial tumours. Each image is from a x20 microscope enlargement. (Panel A) Normal tissue. (Panel B) Papillary urothelial neoplasm of low malignant potential. (Panel C) Non-invasive low grade papillary urothelial carcinoma. (Panel D) Non-invasive, high grade papillary urothelial carcinoma.

investigated in human normal bladder mucosa and in noninvasive urothelial neoplasias.

\section{Materials and methods}

Cell cultures and tissues. The human bladder cell lines (RT112; HT-1376; TCC-SUP, 5637) were obtained from the American Type Culture Collection (ATCC). HT-1376 and TCC-SUP cells were cultured in Dulbecco's modified Eagle's medium (DMEM) supplemented with $10 \% \mathrm{FCS}$ at $37^{\circ} \mathrm{C}$ with $5 \% \mathrm{CO}_{2}$; RT-112 and 5637 cells were cultured in RPMI1640 supplemented with $10 \% \mathrm{FCS}$ at $37^{\circ} \mathrm{C}$ with $5 \% \mathrm{CO}_{2}$.

For immunohistochemical studies, the material consisted of tissue microarrays comprising 105 bladder biopsies of 39 subjects retrieved from the archives of the Department of Pathology, University of Udine. These specimens were recorded between 1998 and 2004. Nine were cases of normal urothelial mucosa, two were papillary urothelial neoplasia of low malignant potential, 12 were low grade non-invasive papillary urothelial carcinoma and 16 were high grade noninvasive papillary urothelial carcinoma. The tumour grade was assessed according to the 2004 WHO classification of tumours of the urinary system (20).
For RT-PCR studies, in addition to the cell lines described above, specimens from 13 cancer biopsies (7 noninvasive low grade papillary urothelial carcinoma, 6 , high grade non-invasive papillary urothelial carcinoma) and 6 normal mucosa were investigated. Bladders from two 16week-old human embryos were also investigated.

Immunohistochemical staining. Tissue samples were fixed in $4 \%$ buffered formalin, embedded in paraffin, and $5-\mu \mathrm{m}$ sections were cut. Slides were pretreated in $10 \mathrm{mM}$ citrate buffer, $\mathrm{pH} 6.0$ at $98^{\circ} \mathrm{C}$ in a water bath for $50 \mathrm{~min}$, then incubated overnight at $4^{\circ} \mathrm{C}$ with rabbit polyclonal anti-PAX8 antibody diluted 1:200. The specificity of the antibody has already been demonstrated $(24,25)$.

After washing, the immunocomplexes were revealed using the Envision dual link rabbit/mouse HRP revealing system from Dako cytomation.

Isolation of RNA and reverse transcriptase-polymerase chain reaction $(R T-P C R)$ analysis. Total RNA was extracted from cell lines or patient tumour samples (obtained by transurethral resection surgery and quickly frozen in liquid nitrogen), with the classic guanidinium isothiocyanate-acid 
phenol method (26). About $1 \mu \mathrm{g}$ of total RNA was reverse transcribed using a PAX8-specific primer as described by Poleev et al (28). The PCR protocol was that of Poleev et al using the outer primers no. 44 and no. 18 in the first step, followed by a nested PCR with the inner primers no. 19 and no. 45, as previously described (28). This approach allows the amplification of 5 PAX8 isoforms (from A to E: 550, $361,471,240$ and $138 \mathrm{bp}$-long respectively) that were visualized on $2 \%$ agarose gel $0.5 \mathrm{X}$ TBE. PCR products were verified by sequencing.

\section{Results}

The expression of PAX8 during kidney development has been extensively reported $(8,9,11)$. For this reason, we decided to investigate PAX8 expression in normal bladder mucosa and in non invasive urothelial neoplasias. Papillary urothelial neoplasia of low malignant potential, low grade non-invasive papillary urothelial carcinoma and high grade non-invasive papillary urothelial carcinoma were investigated. PAX8 expression was evaluated by immunohistochemistry using a validated polyclonal antibody $(24,25)$. Fig. 1 shows representative images of PAX8 expression. Quantitative data are shown in Table I. No PAX8 expression was observed in any of the cases of normal urothelial mucosa. In contrast, nuclear PAX8 expression was detectable in $2 / 2,10 / 12$ and $16 / 16$ urothelial neoplasia of low malignant potential, noninvasive low grade and non-invasive high grade carcinomas, respectively. In the positive samples a large portion of the cells was stained. No significant difference was observed between different biopsies from the same patient. Thus, PAX8 was not expressed in normal adult bladder, but it was expressed in the majority of non-invasive urothelial neoplasias.

In order to extend the data obtained by immunohistochemistry, the presence of PAX8 mRNA in normal bladder mucosa and in non-invasive urothelial neoplasia was
Table I. PAX8 expression in normal urothelial mucosa and urothelial papillary carcinomas.

\begin{tabular}{lccc}
\hline $\begin{array}{l}\text { Sample } \\
\text { categories }\end{array}$ & $\begin{array}{c}\text { No. of } \\
\text { cases }\end{array}$ & $\begin{array}{c}\text { No. of } \\
\text { positive cases }\end{array}$ & $\begin{array}{c}\text { \% of cell } \\
\text { positivity }\end{array}$ \\
\hline Normal mucosa & 9 & 0 & - \\
Pap. LMP & 2 & 2 & 67 \\
Pap. NI-L & 12 & 10 & 53 \\
Pap. NI-H & 16 & 16 & 62 \\
\hline
\end{tabular}

Pap. LMP, papillary urothelial neoplasm of low malignant potential; Pap. NI-L, non-invasive low grade papillary urothelial carcinoma; Pap. NI-H, non-invasive high grade papillary urothelial carcinoma.

investigated by RT-PCR. Since PAX8 mRNA is subjected to alternative splicing $(27,28)$, a method to detect the various PAX8 splicing mRNA isoforms was used (28). As a positive control, the human BCPAP cell line, derived from a papillary thyroid carcinoma (29), was utilized. Representative results are shown in Fig. 2. Confirming the immunohistochemical data, PAX8 mRNA was not observed in normal mucosa. Whereas, PAX8 was present in each of the non-invasive urothelial neoplasias investigated. In terms of the splicing isoforms, PAX8 expression was extremely heterogeneous, with the different isoforms differentially represented in the various non invasive urothelial neoplasias. PAX8 is expressed in the kidney only during development $(8,9,11)$. Therefore, the presence of the various PAX 8 mRNA isoforms was evaluated in the bladder of two 16-week-old human embryos. Panel B of Fig. 2 shows a representative image of PAX8 expression in a bladder embryo. Only isoform A was present in the developing bladder, suggesting that the PAX8 splicing isoforms B, C, D and E may be the
$\mathbf{A}$
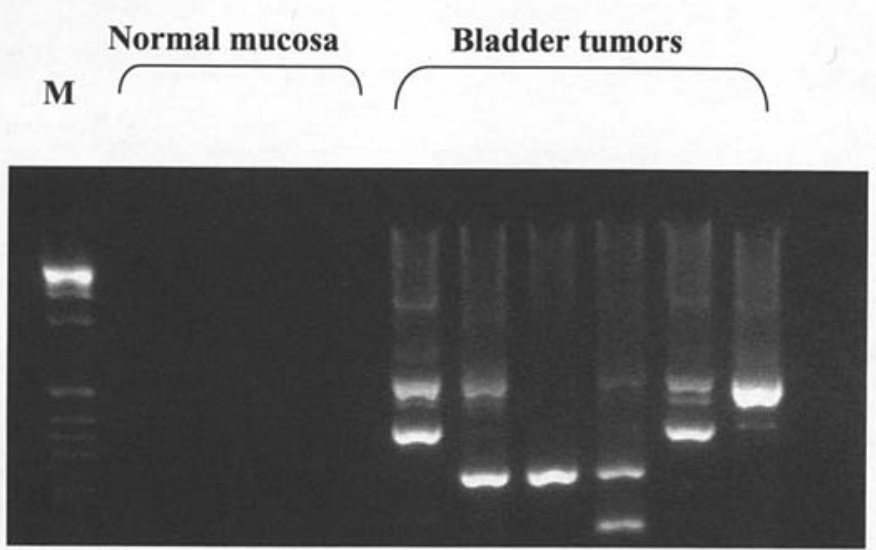
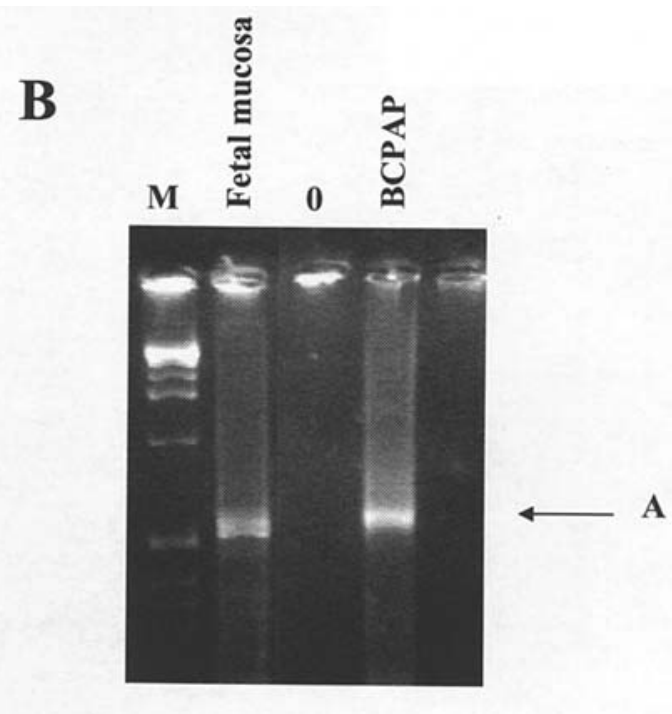

Figure 2. RT-PCR detection of PAX8 mRNA in the normal bladder and UCs. Evaluation of PAX8 expression by RT-PCR. (Panel A) PAX8 expression in non-invasive urothelial tumors. (Panel B) PAX8 expression in a 16 week-old human fetus. In both panels the lane 0 indicate RT-PCR lacking cDNA and the lane BCPAP indicates a thyroid tumour cell line used as a positive control. 


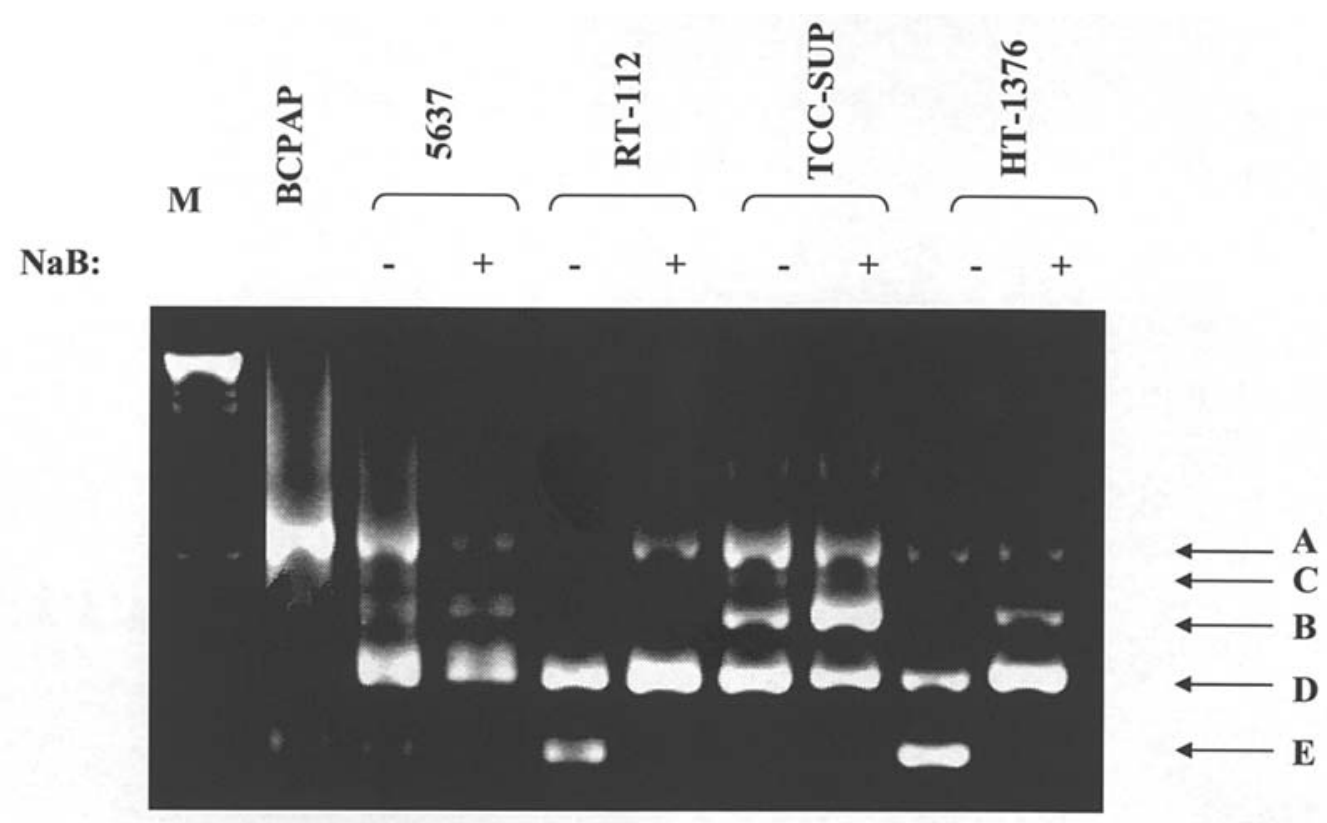

Figure 3. Effects of $\mathrm{NaB}$ on PAX8 splicing isoforms in bladder tumour cell lines. Each line was treated or not with $\mathrm{NaB}$ ( $3 \mathrm{mM}$, for $28 \mathrm{~h})$ and PAX8 splicing isoforms were evaluated by RT-PCR.

consequence of cancer-specific modifications of the splicing process.

In order to extend the data on splicing form heterogeneity, several cell lines derived from different grade bladder tumours (5637, RT-112, TCC-SUP and HT-1376) were analyzed. The cell lines were treated or not with sodium butyrate ( $\mathrm{NaB} 3 \mathrm{mM}$, for $28 \mathrm{~h}$ ), which is a known modulator of the splicing machinery (30). The results are shown in Fig. 3. Confirming data obtained in the bladder tumours, the cell lines showed heterogeneity of the PAX8 splicing isoforms. The D isoform was present in all the cell lines and was not modified by the $\mathrm{NaB}$ treatment. The $\mathrm{E}$ isoform was present in the RT-112 and HT-1376 cells and disappeared upon $\mathrm{NaB}$ treatment. The $\mathrm{A}$ isoform was expressed at significant levels only in the 5637 and TCC-SUP cells. NaB treatment induced a decrease of the A isoform in the 5637 cells. In RT-112 cells, the A isoform was evident only upon $\mathrm{NaB}$ treatment. The $\mathrm{B}$ isoform was significantly induced by $\mathrm{NaB}$ only in the HT-1376 cells. In terms of the cell lines, $\mathrm{NaB}$ treatment induced significant changes of PAX8 mRNA isoforms expression in the 5637, RT-112 and HT-1376 cells, but not in TCC-SUP cells. These data indicate that only a subset of molecular events that determine the PAX8 mRNA splicing heterogeneity is sensitive to $\mathrm{NaB}$ treatment.

\section{Discussion}

The most relevant finding of the present investigation is that PAX8 is expressed in the majority of non-invasive urothelial neoplasia, but not in normal adult urothelial epithelium. Moreover, our data indicate that PAX8 is expressed during normal bladder development. Thus, the PAX8 expression in bladder tumours suggests that the dedifferentiation of these neoplasms occurs through the reactivation of the embryonal urothelial transcriptional programme. The PAX8 re-appearance in tumours suggests that the UC cells have 'regressed' in an ontogenic sense and their properties may therefore be understood clearly by reference to the normal developing cells rather than cells of a mature urothelial epithelium. However, we have shown that the splicing patterns observed in bladder tumours are different to those observed in the developing bladder. Thus, the 'regression' to the embryonal state is associated to transformation-specific modifications of the splicing process. Modification of the normal splicing pattern during cell transformation has been also observed for PAX5. Borson et al, have reported that, in contrast to normal PAX5 expression, multiple isoforms of PAX5 occur in B cells from multiple myeloma patients (32).

Treatment of EBV-tranformed lymphoid cell lines with $\mathrm{NaB}$ induced the modification of the splicing of exon 7 of the SMN1 gene, but not modification of splicing of exons 3 and 5 of the same gene (30). Our data confirm the notion that the $\mathrm{NaB}$ effect is splicing-type specific. In bladder tumour cell lines, $\mathrm{NaB}$ treatment always induces the disappearance of the PAX8 splicing isoform $\mathrm{E}$, but does not induce modification of the PAX8 splicing isoform D.

Our findings indicate that the $\mathrm{NaB}$ effect, in addition to the splicing-type specificity, has also cell-type specificity. Upon $\mathrm{NaB}$ treatment, splicing isoform $\mathrm{A}$ is increased only in RT-112 cells, while isoform B is increased only in HT-1376 cells. $\mathrm{NaB}$ is able to modify mRNA splicing through the inibition of histone deacetylase (31), which increases the expression of a subset of splicing factors (30). Since the $\mathrm{NaB}$ effect on PAX8 mRNA isoforms is splicing-type specific and cell-type specific, we suggest that in distinct bladder tumours, different modifications of the splicing factors expression may occur.

The expression of PAX8 in UCs, but not in normal adult urothelial cells, may suggest that the expression of this transcription factor contributes to the biological abnormalities of 
transformed cells. It has been previously shown, that PAX8 may act as an oncogene when overexpressed (4). Moreover, the proliferation rate of thyroid follicular cells is reduced by inducing the decrease of PAX8 protein levels (33). PAX8 expression may contribute to urothelial tumorigenesis through p53. It has been shown, that PAX8 inhibits p53 expression (6) and that p53 deficiency determines urothelial cell proliferation $(34,35)$.

The expression of PAX genes in bladder cancer has been observed in previous investigation $(36,37)$. In particular, Muratoska and colleagues have shown that the EJ cell line, derived from a G3 human bladder carcinoma, expresses several PAX genes. In addition, it was shown that in the EJ cell line, by using siRNA technology to block PAX2 expression, a strong inhibition of proliferation occurs, suggesting an important role for PAX2 in cell growth.

PAX5 has been found to be expressed in $79 \%$ of primary UCs (34), with a significant positive correlation with growth aggressiveness. Thus, PAX5 the expression has been proposed as a marker of malignancy. Accordingly, PAX5 is also highly overexpressed in most aggressive forms of malignant astrocytoma (38). However, other data suggest that PAX5 is frequently expressed $(93.3 \%$, only considering immunohistochemical results) in bladder tumours, without any relevant correlation either with stage, or with the grade of the tumours (39). The data described in this study are similar: PAX8 is expressed in all the different stages of UCs analyzed. Moreover, different cell lines derived from different stages of UCs display PAX8 expression, suggesting that our observation should be extended also to infiltrating and invasive urothelial neoplasias.

Because of the low sensitivity of urinary cytological diagnosis of urinary bladder carcinoma, several molecular markers have been proposed to this task, including telomerase, microsatellites, matrix metalloproteinases, survivin, and cytokeratins (40-43). PAX8 expression in UCs, but not in normal urothelial epithelium, would make this molecule a candidate for the non-invasive early detection of bladder cancer by molecular analysis of urine.

\section{Acknowledgments}

The authors thank the technicians Alessandra Franzoni, Chiara Fantini, Denis Pivetta and Matteo De Luca for their valuable work. This study was funded by MIUR grants (COFIN) to R.D.L. and G.D. C.P. is supported by a grant from Associazione Italiana Ricerca Cancro (AIRC).

\section{References}

1. Walther C, Guenet JL, Simon D, Deutsch U, Jostes B, Goulding MD, Plachov D, Balling R and Gruss P: Pax: a murine multigene family of paired box-containing genes. Genomics 11: 424-434, 1991.

2. Strachan T and Read AP: PAX genes. Curr Opin Genet Dev 4: 427-438, 1994.

3. Mansouri A, Hallonet M and Gruss P: PAX genes and their roles in differentiation and development. Curr Opin Cell Biol 8: 851-857, 1994.

4. Maulbecker C and Gruss P: The oncogenetic potential of PAX genes. EMBO J 12: 2361-2367, 1993.

5. Stuart ET: Mammalian PAX genes. Annu Rev Genet 27: 219-236, 1993.

6. Read AP: PAX genes - Paired feet in three camps. Nat Genet 9: 333-334, 1995.
7. Damante G, Tell G and Di Lauro R: A unique combination of transcription factors controls differentiation of thyroid cells. Prog Nucleic Acid Res Mol Biol 66: 307-356, 2001.

8. Plachov D, Chowdhury K, Walther C, Simon D, Guénet JL and Gruss P: PAX 8, a murine paired box gene expressed in the developing escretory system and thyroid gland. Development 110: 643-651, 1990

9. Poleev A, Fickenscher H, Mundlos S, Winterpacht A and Zabel B: PAX 8, a human paired box gene: isolation and expression in developing thyroid, kidney and Wilms' tumor. Development 116: 611-662, 1992.

10. Mansouri A, Chowdhury K and Gruss P: Follicular cells of the thyroid gland require PAX 8 gene function. Nat Genet 19: 87-90, 1998.

11. Bouchard M, Souabni A, Mandler M, Neubuser A and Busslinger M: Nephric lineage specification by PAX2 and PAX8: Genes Dev 16: 2958-2970, 2002

12. Dressler GR and Douglass EC: PAX 2 is a DNA-binding protein expressed in embryonic kidney and Wilms tumor. Proc Natl Acad Sci USA 89: 1179-1183, 1992.

13. Eccles MR, Yun K, Reeve AE and Fidler AE: Comparative in situ hybridization analysis of PAX2, PAX8, and WT1 gene transcription in human fetal kidney and Wilms' tumors. Am J Pathol 146: 40-45, 1992.

14. Dehbi M and Pelletier J: PAX8-mediated activation of the wt1 tumor suppressor gene. EMBO J 15: 4297-4306, 1996.

15. Dehbi M, Ghahremani M, Lechner M, Dressler G and Pelletier J: The paired-box transcription factor PAX2 positively modulates expression of the Wilms' tumor suppressor gene (WT1). Oncogene 13: 447-453, 1996.

16. Stuart ET, Haffner R, Oren M and Gruss P: Loss of p53 function through PAX-mediated transcriptional repression. EMBO J 14: 5638-5645, 1995.

17. Macchia PE, Lapi P, Krude H, Pirro MT, Missero C, Chiovato L, Souabni A, Baserga M, Tassi V, Pinchera A, Fenzi G, Gruters A, Busslinger M and Di Lauro R: PAX8 mutations associated with congenital hypothyroidism caused by thyroid dysgenesis. Nat Genet 19: 83-86, 1995.

18. Fabbro D, Di Loreto C, Beltrami CA, Belfiore A, Di Lauro R and Damante G: Expression of thyroid specific transcription factors TTF-1 and PAX 8 in human thyroid neoplasm. Cancer Res 54: 4744-4749, 1994.

19. Jemal A, Clegg LX, Ward E, Ries LA, Wu X, Jamison PM, Wingo PA, Howe HL, Anderson RN and Edwards BK: Annual report to the nation on the status of cancer, 1975-2001, with a special feature regarding survival. Cancer 101: 3-27, 2004.

20. Eble JN, Sauter G, Epstein JI and Sesterhenn IA: Tumours of the urinary system. The World Health Organization Classification of Tumours, Pathology and genetics of Tumours of the urinary system and male genital organs. IARC press, Lyon, pp91-123, 2004.

21. Adshead JM, Kessling AM and Ogden CW: Genetic initiation, progression and prognostic markers in transitional cell carcinoma of the bladder: a summary of the structural and transcriptional changes, and the role of developmental genes. $\mathrm{Br}$ J Urol 82: 503-512, 1998 .

22. Dyrskjot L, Kruhoffer M, Thykjaer T, Marcussen N, Jensen JL, Moller K and Orntoft TF: Gene expression in the urinary bladder: a common carcinoma in situ gene expression signature exists disregarding histopathological classification. Cancer Res 64: 4040-4048, 2004.

23. Sanchez-Carbayo M, Socci ND, Charytonowicz E, Lu M, Prystowsky M, Childs G and Cordon-Cardo C: Molecular profiling of bladder cancer using cDNA microarrays: defining histogenesis and biological phenotypes. Cancer Res 622: 6973-6980, 2002.

24. Fabbro D, Pellizzari L, Mercuri F, Tell G and Damante G: Pax-8 protein levels regulate thyroglobulin gene expression. $J$ Mol Endocrinol 211: 347-354, 1998.

25. Mascia A, Nitsch L, Di Lauro R and Zannini M: Hormonal control of the transcription factor Pax 8 and its role in the regulation of thyroglobulin gene expression in thyroid cells. $\mathbf{J}$ Endocrinol 172: 163-176, 2002.

26. Chomczynsky P and Sacchi N: Single-step method of RNA isolation by acid guanidium thiocyanate-phenol-chloroform extraction. Anal Biochem 162: 156-159, 1987.

27. Kozmik Z, Kurzbauer R, Dorfler P and Busslinger M: Alternative splicing of Pax-8 gene transcripts is developmentally regulated and generates isoforms with different transactivation properties. Mol Cell Biol 10: 6024-6035, 1993. 
28. Poleev A, Wendler F, Fickenscher H, Zannini MS, Yaginuma K, Abbott $C$ and Plachov D: Distinct functional properties of three human paired-box-protein, PAX8, isoforms generated by alternative splicing in thyroid, kidney and Wilms' tumors. Eur J Biochem 228: 899-911, 1995.

29. Fabien N, Fusco A, Santoro M, Barbier Y, Dubois PM and Paulin C: Description of a human papillary thyroid carcinoma cell line. Morphologic study and expression of tumoral markers. Cancer 73: 2206-2212, 1995.

30. Chang JC, Hsieh-Li HM, Jong YJ, Wang NM, Tsai CH and Li H: Treatment of spinal muscular atrophy by sodium butyrate. Proc Natl Acad Sci USA 98: 9808-9813, 2001.

31. Puppin C, D'Aurizio F, D'Elia AV, Cesaratto L, Tell G, Russo D, Filetti S, Ferretti E, Tosi E, Mattei T, Pianta A, Pellizzari L and Damante G: Effects of histone acetylation on sodium iodide symporter promoter and expression of thyroid-specific transcription factors. Endocrinology 146: 3967-3974, 2005.

32. Borson ND, Lacy MQ and Wettstein PJ: Altered mRNA expression of Pax 5 and Blimp-1 in B cells in multiple myeloma. Blood 100: 4629-4639, 2002.

33. Rossi DL, Acebron A and Santisteban P: Function of the homeo and paired domain proteins TTF- 1 and Pax-8 in thyroid cell proliferation. J Biol Chem 270: 23139-2342, 1995.

34. Gao J, Huang HY, Pak J, Cheng J, Zhang ZT, Shapiro E, Pellicer A, Sun TT and Wu XR: p53 deficiency provokes urothelial proliferation and synergizes with activated Ha-ras in promoting urothelial tumorigenesis. Oncogene 23: 687-696, 2004.

35. Shaw NJ, Georgopoulos NT, Southgate J and Trejdosiewicz LK: Effects of loss of p53 and p16 function on life span and survival of human urothelial cells. Int J Cancer 116: 634-639, 2005.
36. Adshead JM, Ogden CW, Penny MA, Stuart ET and Kessling AM: The expression of PAX 5 in human transitional cell carcinoma of the bladder: relationship with de-differentiation. BJU International 83: 1039-1044, 1999.

37. Muratovska A, Zhou C, He S, Goodyer P and Eccles MR: Paired-Box genes are frequently expressed in cancer and often required for cancer cell survival. Oncogene 22: 7989-7997, 2003.

38. Stuart ET, Kioussi C, Aguzzi A and Gruss P: PAX5 expression correlates with increasing malignancy in human astrocytomas. Clin Cancer Res 1: 207-214, 1995.

39. Babjuk M, Soukup V, Mares J, Duskova J, Sedlacek Z, Trkova M, Pecen L, Dvoracek J, Hanus T, Kocvara R, Novak J and Povysil C: The expression of PAX5, p53 immunohistochemistry and p53 mutation analysis in superficial bladder carcinoma tissue. Correlation with pathological findings and clinical outcome. Int Urol Nephrol 34: 495-501, 1995.

40. Little B: Non-invasive methods of bladder cancer detection. Int Urol Nephrol 35: 331-343, 1995.

41. Dettlaff-Pokora A, Matuszewski M and Schlichtholz B: Telomerase activity in urine sediments as a tool for noninvasive detection of bladder cancer. Cancer Lett 222: 83-88, 2005.

42. Weikert S, Krause H, Wolff I, Christoph F, Schrader M, Emrich T, Miller K and Muller M: Quantitative evaluation of telomerase subunits in urine as biomarkers for noninvasive detection of bladder cancer. Int J Cancer 117: 274-280, 2005.

43. Christoph F, Muller M, Schostak M, Soong R, Tabiti K and Miller K: Quantitative detection of cytokeratin 20 mRNA expression in bladder carcinoma by real-time reverse transcriptase-polymerase chain reaction. Urology 64: 157-161, 2005. 